\title{
Title of Review article:
}

The lived Experience of breathlessness for people diagnosed with heart failure: a qualitative synthesis of the literature

\section{Authors:}

Helen Walthall and Theresa Floegel

\section{Authors' affiliations:}

Helen WALTHALL, PhD, RN , Principal Lecturer, Oxford School of Nursing and Midwifery, Oxford Brookes University, Oxford, UK

Theresa FLOEGEL, PhD, MSN, BSN, Assistant Professor, College of Nursing, East Carolina University, 4165E Health Sciences Building, Greenville, NC 27858

\section{Author of correspondence:}

Name: Helen Walthall

Address: Oxford School of Nursing and Midwifery, Faculty of Health and Life sciences, Oxford Brookes University, Jack Straws Lane, Oxford, OX3 OFL/

Telephone number: ++44 1865482603

Email address: hewalthall@brookes.ac.uk 


\section{Abstract:}

Purpose of review:

The experience of breathlessness in patients with heart failure is understudied. This review was aimed at evaluating the most recent qualitative findings regarding the experience of breathlessness in persons diagnosed with heart failure.

Recent findings:

A literature search was conducted using Pubmed, Psycinfo, BNI, Cinahl and Google Scholar including studies on breathlessness experience in patients with heart failure, published between 2017 and 2018. Only 3 studies were identified, and findings were categorized into 5 themes: 1 ) acknowledgement of breathlessness, 2) prevailing consequences of breathlessness, 3) breathlessness in daily life, 4) recognising when breathlessness is a problem, and 5) communicating breathlessness. Understanding the experience of breathlessness was different before and after heart failure diagnosis. Patients experienced similar physical and emotional consequences of breathlessness but varied in strategies to manage the symptom. Patients often do not report breathlessness symptom, or are not asked to describe their symptom by the provider.

\section{Summary:}

Recent studies show those at risk for and those who have heart failure need appropriate education to recognize breathlessness as a critical symptom. Additionally, adequate communication between patients and providers of the breathlessness symptom is needed to support management.

\section{Keywords}

Heart failure, breathlessness, patient experience, communication, living with 


\section{Introduction:}

Heart failure is a global health problem that affects millions of people, particularly those over age $70^{1}$. It is a syndrome of many symptoms, all of which can influence a person's quality of life including physical, emotional, and socio-economical dimensions ${ }^{2}$. The two most significant symptoms for patients with heart failure are breathlessness and fatigue ${ }^{3}$. However, it is often the symptom of breathlessness which causes the acute episode requiring health care provider (HCP) attention. Unfortunately, it is one that appears to be inconsistently managed. Breathlessness as a symptom of heart failure has previously been reviewed ${ }^{4-6}$, however, evidence is lacking regarding the experience of breathlessness in patients with heart failure. Our literature search did not find a comprehensive review of the breathlessness experience in patients with heart failure, thus it is difficult to understand this populations' unique experience. The aim of this review was therefore to synthesize recent qualitative findings (published 2017-2018) on how living with breathlessness is perceived by persons with heart failure.

\section{Search Strategy:}

We systematically searched Pubmed, Psycinfo, BNI, Cinahl and Google Scholar for literature using qualitative methods, published between 1 January 2017 and 1 September 2018 including the search terms: chronic heart failure, advanced heart failure, cardiac failure, heart failure, systolic heart failure and diastolic heart failure AND: breathlessness, dyspnoea*, shortness of breath AND: living, experience*, perception*. We restricted articles to adult participants and written in English. Relevant literature was screened for inclusion through review of titles and abstracts. Full-texts of relevant articles were obtained and independently screened by both authors for inclusion in review. Reference lists of relevant studies and reviews were hand searched to identify additional potential studies. Any disagreements on article inclusion were discussed between authors and resolved. Articles were included in the review if they met the following criteria: published between 1 January 2017 and 1 September 2018; utilizing qualitative methodology; included an identifiable sample of participants with heart failure; and focused on breathlessness related to their condition. The database searches identified 109 articles. After removal of duplicates and abstract review, 18 articles underwent full review by both authors. Only 3 articles met full criteria for this review. Although one ${ }^{7 * *}$ is a review of studies spanning back several years and includes a mix of medical diagnoses in addition to heart failure, the synthesis and application of findings demonstrate current perspectives on the topic of breathlessness, thus we felt it was appropriate to include this review. Figure 1 shows the screening process for selection of the 3 articles.

Quality Appraisal

Studies included for review were assessed by both authors for quality using Joanna Briggs Institute (JBI) Critical Appraisal Checklist for Qualitative Research ${ }^{8}$.

Data extraction

Data regarding characteristics of the studies were extracted manually by HW and checked for accuracy by TF. Findings most relevant to the aims of this review were tabled and include reference details, study design and methodology, aim, data collection method, and participants (table 1).

Thematic synthesis analysis

Data were synthesized using principles of thematic analysis in systematic reviews ${ }^{9}$. First, both authors reviewed results of each study, then HW coded text 'line-by-line'; next both authors independently organized the codes and constructed 'descriptive themes'; lastly each author reviewed independently the descriptive themes, then discussed together for agreement of themes. If there was incongruity, the authors systematically reviewed the theme and continued discussion 
until agreement was reached. Together, the authors generated 'analytical themes'. The analytical themes are presented in table 2 .

\section{Results:}

There were 108 participants with heart failure diagnosis across the three studies. Two studies $10^{* *}$, ${ }^{11^{* *}}$ contained exclusive samples of persons with heart failure $(\mathrm{N}=16$ and $\mathrm{N}=25)$; the third study ${ }^{7}$ was a literature review that included the two above mentioned studies and an additional 6 studies with approximately 67 additional study participants with heart failure. Range of sample size across the three studies was 9 to 27. Reviewed studies are presented in Table 1 and all were judged to be of sufficient quality.

\section{Analytical Themes:}

Analysis of the 3 studies elicited 5 analytical themes describing patient's experience with breathlessness: 1) Acknowledgement of breathlessness as a symptom, 2) prevailing consequences of breathlessness, 3) breathlessness in daily life, 4) recognising when breathlessness is a problem, and 5) communicating breathlessness.

\section{Acknowledgement of breathlessness as a symptom:}

In all three studies, patients acknowledged the presence of breathlessness. However, timing of acknowledgement varied greatly, with the majority not fully understanding the link between their heart failure and the symptom of breathlessness. Many patients identified a lack of knowledge of the symptom prior to heart failure diagnosis. This early gap impacted their attitude toward breathlessness ${ }^{10^{* *}, 11^{* *}}$ with some not perceiving it as a meaningful symptom ${ }^{10^{* *}}$. Patients often cited aging and not their heart failure condition as the reason for increased breathlessness ${ }^{7 * *}, 10^{* *}$ or associated it with other comorbidities or simply doing 'too much' ${ }^{10^{* *}}$. Only when breathlessness began to affect certain activities of daily living (ADLs) did patients acknowledge the symptom. After discussion with $\mathrm{HCP}$, patients were able to identify heart failure as a cause. Of interest though, when patients did acknowledge breathlessness, some immediately began normalizing the symptom. Similarly, Walthall et al (2017) $)^{11^{* *}}$ found that patients described their breathlessness differently before and after heart failure diagnosis, however did not equate a worsening of breathlessness with a worsening of their heart failure condition even after diagnosis was known.

\section{Prevailing consequence of breathlessness}

All three papers described the physical and emotional consequences of breathlessness ${ }^{7 * *, 10^{* *}, 11^{* *}}$. This finding is in line with previous findings in patients with heart failure ${ }^{3,12}$. The physical effects manifested in a number of ways, including participants feeling tired or lethargic. Patients described 'gasping for breath' ${ }^{10^{* *}, 11^{* *}}$ or 'feeling as if they were suffocating or drowning' ${ }^{11^{* *}}$. Breathlessness negatively affected patient's ability to walk, shower, care for grandchildren, and participate in social engagements ${ }^{7 * *, 10^{* *}, 11^{* *}}$. Patients also described how breathlessness made them feel uncertain about the future, causing them to be scared, frightened and hopeless ${ }^{11^{* *}}$. However, others described learning to compensate for their breathlessness and adapting life to work breathlessness within it. They would consciously walk slower, do less or prepare in advance for events ${ }^{7^{* *}, 10^{* *}, 11^{* *}}$. This allowed them to feel a sense of control; that breathlessness would not take over their life ${ }^{11^{* *}}$.

\section{Breathlessness in daily life}

Breathlessness as a daily occurrence was common across the three studies. Most patients described breathlessness in the context of their ability to complete $\mathrm{ADLs}^{10^{* *}, 11^{* *}}$; a similar finding in previous studies ${ }^{13,14}$. Patients described self-management activities to control their breathlessness, which were often self-taught and self-learnt ${ }^{11^{* *}}$. Patients felt the need to carry on with daily tasks despite the limiting nature of their breathlessness ${ }^{7^{* *}, 10^{* *}}$. Hutchinson et al $(2018)^{7^{* *}}$ described how patients 
used coping strategies for daily breathlessness. 'Engaged coping' included problem solving and social support strategies, whereas "disengaged coping' included suicidal thoughts and hiding from others.

\section{Recognising when breathlessness is a problem}

Many patients discussed how they came to recognise breathlessness as a problem ${ }^{7, * * 10^{* *}, 11^{* *}}$. This was often in the context of ADLs, but also when a family member identified the patient's breathlessness to them ${ }^{7 * * 10^{* *}}$. Taylor et al $(2017)^{10^{* *}}$ highlights it was often the patient's previous life experiences and professional background that influenced whether they viewed breathlessness as a problem that required help from their HCP. A few patients threaded patterns together regarding the 'course' of their breathlessness even if they did not know the cause and were able to recognise it as a problem ${ }^{7 *, 10^{* *}, 11^{* *}}$. Taylor et al $(2017)^{10^{* *}}$ found patients discussed with hindsight a wish they had sought help earlier, knowing something was wrong but feeling the need to carry on as if everything was normal.

\section{Communicating breathlessness}

The reviewed studies described mixed findings regarding how participants communicated their feelings and experience of breathlessness. Some patients found it difficult to rate numerically their breathlessness as they were not familiar with the severity range ${ }^{11^{* *}}$. Patients also had difficulty explaining their breathlessness to HCPs, with the patient feeling the HCP did not appreciate the effect of the symptom on the individual ${ }^{7^{* *}}$. Patients also noted during HCP visits they would be at rest and their breathing was calm, thus making it difficult for the provider to evaluate the impact of their breathlessness. A few patients and their carers felt this meant the provider felt nothing else could be done for them and they felt breathlessness was now considered a normal part of life for the patient $^{7 * *}$. Taylor et al (2017) $)^{10^{* *}}$ found somewhat different results. Although patients were not clear on terminology used during diagnosis, they felt once a diagnosis of HF was made their HCP was able to help them manage their breathlessness symptom.

\section{Discussion:}

This study reviewed recent qualitative evidence of patients' experience of breathlessness in heart failure. The thematic synthesis in this review highlights new and compelling insights regarding the acknowledgement of breathlessness as a symptom and recognizing when it is a problem and communicating breathlessness. It is often perceived by older people as part of the ageing process, indicating they may find it difficult to first detect breathlessness, and then to report it as a symptom ${ }^{15}$. Our review shows there is a difference between patients' perceptions of breathlessness before and after a diagnosis of heart failure is known. Symptom recognition and reporting are key areas for HCPs to focus with at-risk patients as these individuals may delay or avoid contacting their HCP despite experiencing breathlessness ${ }^{16}$. However, diagnosis of heart failure may or may not provide a better understanding of breathlessness as a symptom for patients. As seen in this review patients did not perceive increased breathlessness as an indication of worsening heart failure $7^{* *}, 10^{* *}, 11^{* *}$. Our findings are in line with those of Grant et al $2018^{17^{* *}}$, who describe their heart failure study sample struggling with symptoms and adherence in the first month post-hospitalization.

Self-management strategies are key to managing heart failure symptoms ${ }^{18}$, including breathlessness. Our review found that patients described self-learning regarding breathlessness rather than instruction from $\mathrm{HCPs}^{7 * *, 10^{* *}, 11^{* *}}$. This finding may be supported by other studies in which patients reported adjusting to living at home with no information about their diagnosis, or feeling abandoned and having to develop their own strategies for managing their symptoms ${ }^{19,20}$. Self-care programmes have been shown to improve outcomes and reinforce education in patients with heart failure ${ }^{21}$. The level of symptom burden may be important for driving self-care strategies. The greater the symptom burden the higher the self-care engagement was, indicating symptoms are an important factor in self-care behaviours ${ }^{22^{*}}$. However, one study showed that though patients were able to apply self-care strategies, they were unable to interpret symptom changes in the context of heart 
failure, leaving them at risk for hospitalisation ${ }^{23}$. These findings support the need for tailored education related to a patient's disease progression.

A key finding in our review was that communication of breathlessness was a significant factor affecting management of the symptom. Patient descriptions of lack of communication suggest the lived experience of breathlessness may be mostly hidden from HCPs. Additionally how patients perceive breathlessness compared to the assessment of the HCP appears to differ. Some of the patient quotes in our reviewed studies support findings that older people report breathlessness to be twice as burdensome compared to HCPs' assessment of their symptom ${ }^{15}$. Additionally, patients in our review found communication through assessment tools was not effective ${ }^{11^{* *}}$. Our findings are in line with Alpert et al (2017) ${ }^{24}$, who found use of assessment tools did not help communication of breathlessness between patients with heart failure and their HCP. In cases of miscommunication, it may be that HCPs are not asking the right questions. Instead of asking 'are you breathless?' when the patient is calmly sitting for an exam, it may be beneficial to ask 'how does your breathlessness affect you at home?' as this may be more meaningful to the patient and elicit accurate information.

\section{Conclusion:}

This synthesis highlights that patients with heart failure who experience breathlessness are often left feeling unsure of the significance of the symptom and what symptom changes mean about their condition. Clear communication between patients and HCPs should enable the patient to communicate the symptom of breathlessness in a meaningful way. This in turn would enable the HCP to accurately assess the symptom and work with the patient to develop strategies to manage their breathlessness.

\section{Key points:}

- Breathlessness in patients with heart failure was widespread consequence to their daily life

- Patients with heart failure who experience breathlessness feel unsure of the significance of the symptom and what changes meant to their condition

- There needs to be meaningful communication between patients and health care providers to enable breathlessness to be managed effectively

\section{Acknowledgements:}

None

\section{Financial Support and sponsorship:}

None

\section{Conflicts of Interest:}

None to report 


\section{References and recommended reading:}

Papers of particular interest, published within the annual period of review have been highlighted as: *Special interest

** of outstanding interest

1. Ambrosy AP, Fonarow GC, Butler J, Chioncel $O$ et al. the global health and economic burden of hospitalizations for heart failure. J Am Coll Cardiol 2014;63:1123-33.

2. Heo S, Lennie TA, Okoli C, Miser DK. Quality of life in patients with heart failure: ask the patients. Heart Lung 2009;38(2):100-108.

3. Herr JK, Salyer J, Lyon DE, Goodloe L, et al. Heart failure symptom relationships: a systematic review. J Cardiovasc Nurs 2014;29:416-422.

4. Johnson MJ, Oxberry SG, Cleland JGF, Clark AL. Management of breathlessness in clinical trials in patients with heart failure: the need for standardised approach: a systematic review. Eur J Heart Fail 2010;12:137-147.

5. Oxberry SG, Johnson MJ. Review of the evidence for the management of dyspnoea in people with chronic heart failure. Curr Opin Support Palliat Care. 2008;2:84-88.

6. Kewkkeboom KL, Bratzke LC. A systematic review of relaxation, mediation and guided imagery strategies for symptom management in heart failure. J Cardiovasc Nurs 2016;31:457-468.

7. Hutchinson A, Barclay-Klingle N, Galvin K, Johnson MJ. Living with breathlessness: a systematic literature review and qualitative synthesis. Eur Respir J 2018;51:1701477 **

A qualitative synthesis of living with breathlessness from a medical condition but also from perspective of carers and clinicians

8. Lockwood C, Munn Z, Porritt K. Qualitative research synthesis: methodological guidance for systematic reviewers utilizing meta-aggregation. Int J Evid Based Healthc. 2015;13(3):179-187.

9. Thomas J, Harden A. Methods for the thematic synthesis of qualitative research in systematic reviews. BMC Medical Research Methodology 2008; 8: 45. doi:10.1186/1471-2288-8-45

10. Taylor CJ, Hobbs FDR, Marshal T, Leyva-Leon F. From breathless to failure: symptom onset and diagnostic meaning in patients with heart failure - a qualitative study. BMJ Open 2017;

7(3):e013648. **

A qualitative study exploring the patients perspective of breathlessness on a diagnostic journey from the first experience of breathlessness to being given a diagnosis

11. Walthall $\mathrm{H}$, Jenkinson $\mathrm{C}$, Boulton $\mathrm{M}$. Living with breathlessness in chronic heart failure: a qualitative study. J Clin Nurs 2017;26:2036-2044. *

Qualitative data exploring how breathlessness is experienced in patients diagnosed with heart failure and how daily life is affected and how adjustments are made to manage the symptom.

12. Kupper N, Bonhof C, Westerhuis B, Widdershoven J et al. Determinants of Dypsnea in Chronic Heart Failure. J Card Fail 2016;22:201-209. 
13. Dunlay SM, Manemann SM, Chamberlain AM, Cheville AL et al. Activities of Daily Living and Outcomes in Heart Failure. Circ Heart Fail 2015;8:261-267.

14. Rodriquez KL, Appelt CJ, Switzer GE, Sonel Al et al. "They diagnosed bad heart": A qualitative exploration of patients knowledge about and experience with heart failure. Heart Lung 2008;37:257-265.

15. Riegel B, Dickson VV, Cameron J, Johnson JC et al. Symptom recognition in elders with heart failure. J Nurs Scholar 2010;42:92-100.

16. Jurgens CY, Lee CS, Reigel B. Psychometric analysis of the heart failure somatic perception scale as a measure of patient symptom perception J Cardiovasc Nurs 2017:32(2):140-147

17. Grant JS, Graven LJ, Fuller K. Problems experienced in the first month after discharge from a heart failure related hospitalization. J Patent Cent Res Rev 2018;5:140-148.

This study shows how patients manage their symptoms in the first month post discharge and how the problems experienced impact on their lives

18. Lainscak M, Blue L, Clark AL, Dahlstrom Ulf et al. Self Care Management of heart failure: practical recommendations from the patient care committee of the Heart Failure Association of the European Society of Cardiology. Eur J Heart Fail 2011;13:115-126.

19. Andersson L, Erickson I, Nordgen L. Living with heart failure without realising: a qualitative patient study Br J Comm Nurs 2012;17:630-637.

20. Gysels M, Higginson IJ. The lived experience of breathlessness and its implications for care: a qualitative comparison in cancer, COPD, heart failure and MND. BMC Palliat Care 2011;10:15.

21. Liou H-L, Chen H-I, Hsu S-C, Lee S-C et al. The effects of a self-care program on patients with heart failure. J Chin Med Assoc 2015;78:648-656.

22. Auld JP, Mudd JO, Gelow JM, Lyons KS et al. Patterns of heart failure symptoms are associated with self-care behaviors over 6 months. Eur J Cardiovasc Nurs 2018;17:543-551. *

This study showed that patients who experience more problems with symptoms are more engaged with self-care activities over time

23. Reeder K, Ercole P, Peek G, Smith C. Symptom perceptions and self care behaviours in patients with self-manage heart failure. J Cardiovasc Nurs 2015;30:E1-E7.

24. Alpert CM, Smith MA, Hummell SC, Hummell EK. Symptom burden in Heart Failure: assessment, impact on outcomes and management. Heart Fail Rev 2017;22:25-39. 
Table 1. Characteristics of reviewed studies.

\begin{tabular}{|c|c|c|c|c|}
\hline $\begin{array}{l}\text { Author } \\
\text { (date) }\end{array}$ & $\begin{array}{l}\text { Study Design or } \\
\text { Methodological } \\
\text { Approach }\end{array}$ & Aim & $\begin{array}{l}\text { Data } \\
\text { Collection }\end{array}$ & Participants \\
\hline $\begin{array}{l}\text { Hutchinson } \\
\text { et al } \\
(2018)^{7}\end{array}$ & $\begin{array}{l}\text { Systematic } \\
\text { literature review } \\
\text { and Qualitative } \\
\text { synthesis }\end{array}$ & $\begin{array}{l}\text { To explore qualitative research on } \\
\text { the experience of and response to } \\
\text { breathlessness due to a variety of } \\
\text { medical conditions, by those living } \\
\text { with it, those who care for them } \\
\text { and clinicians who treat them, }\end{array}$ & $\mathrm{N} / \mathrm{A}$ & $\begin{array}{l}\text { 5/101 studies were heart failure } \\
\text { participants only; a further } 5 \\
\text { studies identify explicitly } \\
\text { participants with heart failure } \\
\text { within a mixed study population }\end{array}$ \\
\hline $\begin{array}{l}\text { Taylor et al } \\
(2017)^{10}\end{array}$ & $\begin{array}{l}\text { In-depth } \\
\text { interview study }\end{array}$ & $\begin{array}{l}\text { To explore the experiences of } \\
\text { patients with a recent diagnosis of } \\
\text { heart failure with a focus on the } \\
\text { symptom onset and diagnosis } \\
\text { parts of the pathway to explore } \\
\text { how and when patients realised } \\
\text { something was } \\
\text { wrong and what the term 'heart } \\
\text { failure' means to them. }\end{array}$ & $\begin{array}{l}\text { Semi- } \\
\text { structured } \\
\text { interviews }\end{array}$ & $\begin{array}{l}\mathrm{N}=16 \\
\text { Mean age } 78.5 \text { yrs (range } 52-87 \text { ) } \\
\text { Female } 31.3 \% \\
\text { Participants diagnosed with } \\
\text { heart failure }<1 \text { year. }\end{array}$ \\
\hline $\begin{array}{l}\text { Walthall et } \\
\text { al }(2017)^{11}\end{array}$ & $\begin{array}{l}\text { Descriptive } \\
\text { qualitative } \\
\text { design }\end{array}$ & $\begin{array}{l}\text { to explore how patients } \\
\text { themselves describe their } \\
\text { experiences of breathlessness, } \\
\text { how } \\
\text { breathlessness affects their daily } \\
\text { lives and how they adjust to and } \\
\text { manage it. }\end{array}$ & $\begin{array}{l}\text { Semi- } \\
\text { structured } \\
\text { interviews }\end{array}$ & $\begin{array}{l}\mathrm{N}=25 \text {, } \\
\text { Mean age } 72.7 \text { yrs (range 53-86) } \\
\text { Female } 40 \% \\
\text { Participants diagnosed with } \\
\text { HFrEF; } 92 \% \text { NYHA class III/IV. }\end{array}$ \\
\hline
\end{tabular}

Table 2: Themes and sub-themes from synthesis

\begin{tabular}{|l|l|}
\hline Theme & Sub-theme \\
\hline $\begin{array}{l}\text { 1.Acknowledgement of breathlessness as a } \\
\text { symptom }\end{array}$ & $\begin{array}{l}\text { Understanding the diagnosis } \\
\text { Normalization of symptoms }\end{array}$ \\
\hline 2 Prevailing consequences of breathlessness & $\begin{array}{l}\text { Physical effects } \\
\text { Uncertainty } \\
\text { Compensation }\end{array}$ \\
\hline 3 Breathlessness in daily life & $\begin{array}{l}\text { Self-management of breathlessness } \\
\text { Effect on ADLs }\end{array}$ \\
\hline $\begin{array}{l}\text { 4. Recognising when breathlessness is a } \\
\text { problem }\end{array}$ & Seeking support \\
\hline 5. Communicating breathlessness & $\begin{array}{l}\text { Describing critical events/ terminology } \\
\text { Responsiveness of health provider }\end{array}$ \\
\hline
\end{tabular}


Figure 1: PRISMA flow chart reporting items for systematic review literature searching.
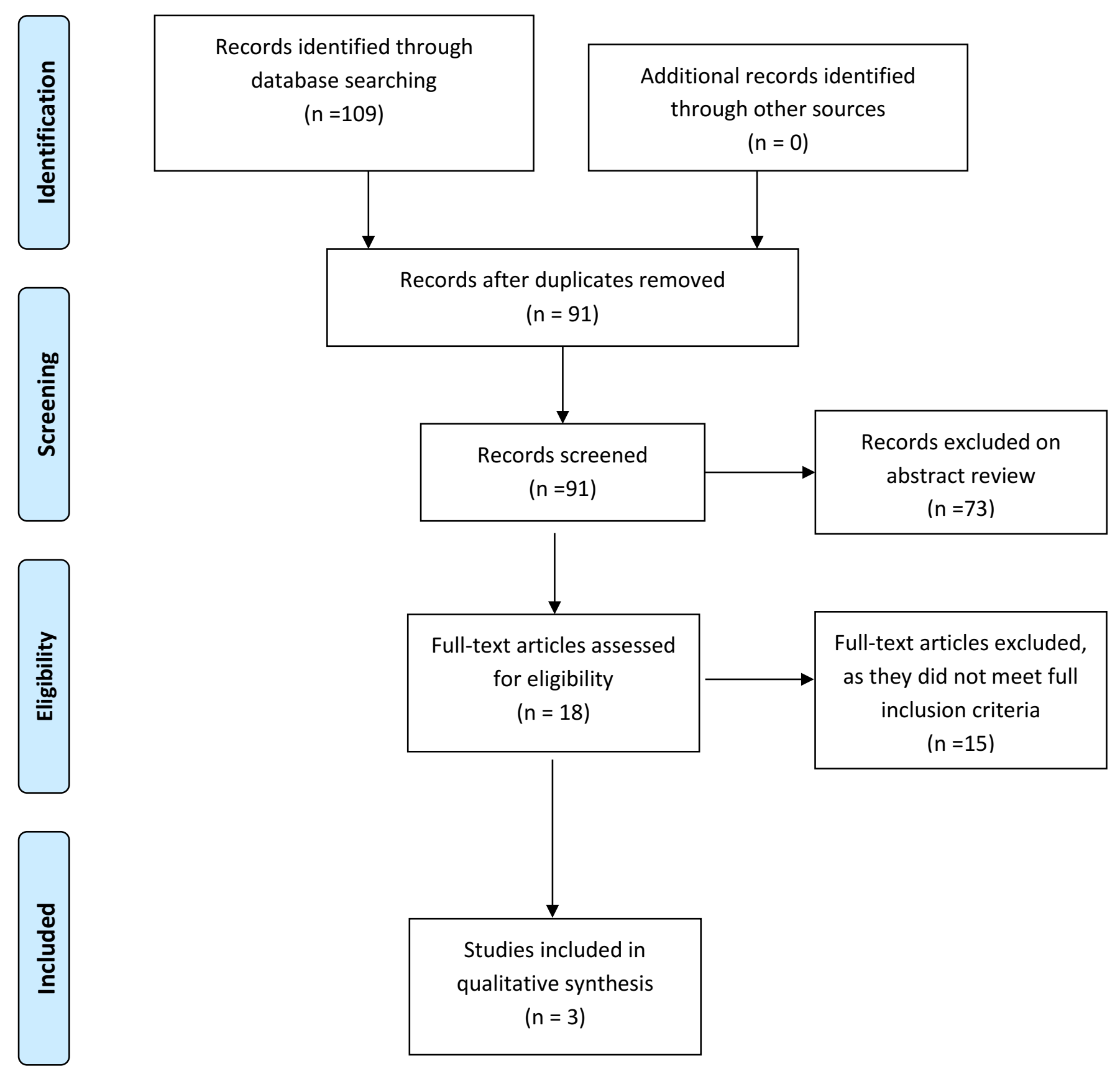